\title{
Analisis Air Sungai Penerima Air Limbah Penambangan Minyak Bumi Secara Tradisional Pada Sumur Tua di Desa Wonocolo Kabupaten Bojonegoro
}

\author{
Yusran Hedar \\ Pusat Pengembangan Sumber Daya Manusia Minyak dan Gas Bumi, Cepu, Blora
}

\section{INFORMASI NASKAH}

Diterima: 25 Pebruari 2021

Direvisi: 3 September 2021

Disetujui: 14 September 2021

Terbit: 15 Nopember 2021

Email korespondensi:

yusranhedar@gmail.com

Laman daring:

https://doi.org/10.37525/

$\mathrm{mz} / 2021-2 / 279$

\begin{abstract}
ABSTRAK
Sumur tua minyak bumi yang ada di Indonesia mencapai 13.824 sumur dan 745 sumur masih aktif. Di beberapa tempat sumur tua ini di eksploitasi dengan cara tradisional salah satunya lapangan minyak di desa Wonocolo. Penambangan minyak yang dilakukan masyarakat masih menggunakan peralatan sederhana. Penambangan tradisional minyak bumi selain memberi dampak positif dalam peningkatan produksi minyak bumi nasional dan pendapatan masyarakat, tetapi juga memiliki dampak negatif yang ditimbulkan yakni pencemaran lingkungan. Limbah utama yang dihasilkan dari kegiatan penambangan minyak adalah air terproduksi, terutama pada sumur tua yang memiliki water cut diatas $90 \%$.

Penelitian ini bertujuan menganalisis kualitas air sungai penerima air limbah kegiatan penambangan tradisional minyak bumi di Desa Wonocolo berdasaran PP Nomor 82 Tahun 2001 dengan fokus pembahasan parameter DO, COD, BOD dan minyak dan lemak. Hasil penelitian menunjukkan kualitas air sungai pada daerah hulu kondisinya masih baik, sedangkan pada daerah hilir beberapa parameter nilainya diatas baku mutu air kelas II.
\end{abstract}

Kata kunci: sumur tua, minyak bumi, air terproduksi, air sungai

\section{ABSTRACT}

There are 13,824 old petroleum wells in Indonesia and 745 wells are still active. In several places these old wells are exploited in traditional ways, one of which is the oil field in Wonocolo village. Oil mining is carried out by the community using simple equipment. Besides having a positive impact on increasing national petroleum production and people's income, traditional petroleum mining also has a negative 
impact, namely environmental pollution. The main waste generated from oil mining activities is produced water, especially in old wells that have a water cut of above $90 \%$.

This study aims to analyze the quality of river water receiving wastewater from traditional petroleum mining activities in Wonocolo Village based on Government Regulation Number 82 Year 2001 with a focus on the discussion of DO, COD, BOD and oil and fat parameters. The results showed that the quality of river water in the upstream area was still in good condition, while in the downstream area several parameters were above the class II water quality standard.

Keywords: old wells, petroleum, produced water, river water

\section{PENDAHULUAN}

Filosofi pengelolaan pertambangan minyak bumi pada sumur tua adalah mengoptimalkan produksi minyak bumi serta meningkatkan kesejahteraan masyarakat di sekitar lokasi sumur tua (Marlena et al, 2015). Menurut Peraturan Menteri Energi Dan Sumber Daya Mineral Nomor 01 Tahun 2008 Tentang Pedoman Pengusahaan Pertambangan Minyak Bumi Pada Sumur Tua yang dimaksud sumur tua merupakan sumur-sumur minyak bumi yang di bor dan di produksi sebelum tahun 1970 dan terletak pada lapangan yang tidak diusahakan pada suatu wilayah kerja pada kontrak kerja sama dan tidak diusahakan lagi oleh kontraktor. Sumur tua minyak bumi yang ada di Indonesia mencapai 13.824 sumur dan 745 sumur masih aktif (Naumi, 2015). Di beberapa tempat sumur tua ini di eksploitasi dengan cara tradisional salah satunya lapangan minyak di desa Wonocolo. Penambangan tradisional minyak bumi yang dilakukan masyarakat selain memberi dampak positif dalam peningkatan produksi minyak bumi nasional dan pendapatan masyarakat, tetapi juga memiliki dampak negatif yang ditimbulkan yakni pencemaran lingkungan, terutama terhadap air permukaan. Selain menghasilkan minyak mentah (crude oil) dalam proses pertambangan minyak bumi dihasilkan air terproduksi dalam jumlah cukup besar karena sumur tua minyak bumi pada umumnya memiliki harga water cut yang tinggi yaitu mencapai diatas $90 \%$ (Raharjo, 2016).

Proses produksi minyak dari sumursumur tersebut masih dilakukan dengan cara tradisional, termasuk proses pemisahan minyak mentah dengan air terproduksi yang dihasilkan masih menggunakan alat sederhana. Karena hal tersebut sangat dimungkinkan banyak ceceran minyak mentah yang terjadi, dan juga pemisahan air dan minyak yang belum sempurna. Sehingga dicurigai air yang dibuang ke dalam badan air masih memiliki nilai kontaminasi diatas baku mutu yang dipersyaratkan. Limbah yang masuk ke air lingkungan menyebabkan terjadinya penyimpangan dari keadaan normal air dan ini berarti suatu pencemaran (Wardhana, 2004). Untuk menjaga pelestarian fungsi lingkungan hidup perlu dilakukan upaya pengendalian terhadap usaha dan kegiatan yang berpotensi menimbulkan pencemaran dan kerusakan lingkungan hidup. Tujuan Penelitian ini yaitu menganalisis kualitas air sungai akibat kegiatan penambangan tradisional minyak bumi pada sumur tua yang ada di desa Wonocolo.

\section{TINJAUAN PUSTAKA}

\section{A. Sungai}

Sungai merupakan alur atau wadah-wadah 
air alami maupun buatan berupa jaringan pengaliran air beserta air di dalamnya mulai dari hulu sampai muara dengan dibatasi kanan dan kirinya oleh garis sempadan (PP No.38 Tahun 2011). Sungai merupakan salah satu sumber air yang banyak dimanfaatkan untuk memenuhi kebutuhan hidup manusia dan makhluk hidup lainnya. Sungai merupakan ekosistem yang penting bagi manusia, sungai juga menyediakan air bagi manusia baik untuk berbagai kegiatan seperti pertanian, industri, maupun domestik (Siahaan et al, 2011). Menurut Mulyanto (2007) ada dua fungsi utama sungai secara alami yaitu mengalirkan air dan mengangkut sedimen hasil erosi pada Daerah Aliran Sungai dan alurnya., kedua fungsi ini terjadi bersamaan dan saling mempengaruhi.

Menurut PP No. 82 Tahun 2001 tentang pengelolaan kualitas air dan pengendalian pencemaran air, air merupakan sumber daya alam yang memenuhi hajat hidup orang banyak, sehingga perlu dilindungi agar dapat tetap bermanfaat bagi hidup dan kehidupan manusia serta makhluk hidup lainnya. Untuk menjaga atau mencapai kualitas air sehingga dapat dimanfaatkan secara berkelanjutan sesuai dengan tingkat mutu air yang diinginkan, maka perlu upaya pelestarian dan atau pengendalian. Pelestarian kualitas air merupakan upaya untuk memelihara fungsi air agar kualitasnya tetap pada kondisi alamiahnya. Pelestarian kualitas air dilakukan pada sumber air yang terdapat di hutan lindung. Sedangkan pengelolaan kualitas air pada sumber air di luar hutan lindung dilakukan dengan upaya pengendalian pencemaran air, yaitu upaya memelihara fungsi air sehingga kualitas air memenuhi baku mutu air.

\section{B. Kualitas Air Sungai}

Kualitas air yaitu sifat air dan kandungan makhluk hidup, zat, energi atau komponen lain yang terdapat di dalam air. Kualitas air juga merupakan istilah yang menggambarkan kesesuaian atau kecocokan air untuk penggunaan tertentu, misalnya air minum, perikanan, perairan/irigasi, industri, rekreasi dan sebagainya (Yuliastuti, 2011). Meningkatnya aktivitas domestik, pertanian dan industri akan mempengaruhi dan memberi dampak terhadap kondisi kualitas air sungai terutama aktivitas domestik yang memberikan masukan konsentrasi BOD terbesar ke badan sungai (Priyambada et al, 2008).

Kualitas air sungai merupakan kondisi kualitatif yang diukur berdasarkan parameter tertentu dan dengan metode tertentu sesuai peraturan perundangan yang berlaku. Kualitas air sungai dapat dinyatakan dengan parameter yang menggambarkan kualitas air tersebut. Parameter tersebut meliputi parameter fisika, kimia dan biologi. Parameter fisika kualitas air dapat menggambarkan kondisi yang dapat dilihat secara visual atau kasat mata, meliputi kekeruhan, suhu, kandungan padatan terlarut, rasa, bau, warna dan sebagainya. Parameter kimia meliputi derajat keasaman $(\mathrm{pH})$, oksigen terlarut (DO), BOD, COD, kandungan logam, kesadahan dan sebagainya. Parameter biologi meliputi kandugan mikroorganisme dalam air (Asdak, 2010).

Agar perairan dapat berfungsi sesuai dengan peruntukannya maka diperlukan batas atau kadar maksimum pencemar yang dapat ditenggang keberadaannya dalam perairan tersebut. Batas atau kadar maksimum itu disebut baku mutu air. Baku mutu air dibedakan menjadi 2 jenis dimana dapat menentukan tindakan pengendalian yang berbeda (Effendi, 2003) :

1) Baku mutu badan air : untuk kadar air sesuai dengan peruntukannya dalam upaya pengendalian pencemaran.

2) Baku mutu limbah cair : untuk membatasi beban limbah dari sumber pencemar.

\section{Air Terproduksi}

Kegiatan eksplorasi dan produksi minyak dan gas bumi menghasilkan limbah kegiatan 
yang berbentuk padat, cair, dan gas dengan komposisi 80\% merupakan limbah cair bahkan pada lapangan minyak yang menua mencapai nilai 95\% (Hasiany et al, 2015). Air terproduksi adalah air (brine) yang dibawa keatas dari strata yang mengandung hidrokarbon selama kegiatan pengambilan minyak dan gas bumi termasuk didalamnya air formasi, air injeksi dan bahan kimia yang ditambahkan untuk pemisahan minyak dan air (Neff, 2002).

Air terproduksi merupakan limbah cair terbesaryang dihasilkanolehkegiatan ekplorasi dan produksi minyak dan gas. Air terproduksi telah mengalami kontak dengan hidrokarbon selama bertahun-tahun, sehingga air ini mengandung sifat-sifat kimia dari hidrokarbon itu sendiri. Sifat-sifat fisik dan kimia dari air terproduksi bervariasi, bergantung pada letak geografisnya dan jenis hidrokarbon yang dihasilkan (Gazali et al., 2017). Sifat Air terproduksi ini mengandung berbagai material organik, anorganik dan unsur-unsur lainnya yang terkandung di dalam minyak dan gas bumi (Ahmadun et al., 2009). Menurut Schifter et al, (2015) dalam Hedar (2018) komposisi air terproduksi sangat bervariasi bergantung letak sumur dan lapangan minyak akan tetapi material utama dalam air terproduksi yang menjadi perhatian khusus adalah kandungan garam, kandungan minyak dan lemak, kandungan senyawa organik dan anorganik. Minyak dan lemak adalah unsur utama dari air terproduksi yang banyak menerima perhatian pada operasi onshore dan offshore, sedangkan kandungan garam (dinyatakan dalam salinitas, konduktivitas, atau TDS) adalah unsur utama dari operasi onshore (Veil et al, 2004). Kandungan material dalam air terproduksi ini menyebabkan air terproduksi terlebih dahulu harus diolah sebelum dibuang ke lingkungan, karena jika tidak akan merusak dan membahayakan lingkungan.

Kegiatan penambangan minyak bumi di lapangan Wonocolo menghasilan limbah cair yang berasal dari hasil kegiatan produksi.
Dalam proses produksinya fluida yang keluar dari mulut sumur kemudian dialirkan kedalam bak penampung atau bak oil catcher yang merupakan tempat memisahkan minyak dan air terproduksi. Sistem pemisahan ini dengan perbedaan berat jenis antara kedua fluida, dimana berat jenis air lebih besar dari berat jenis minyak sehingga minyak akan dominan berada pada permukaan cairan. Minyak yang terkumpul di permukaan cairan kemudian diambil dan dikumpulkan dalam tandon sedangkan air terproduksi akan keluar melalui bagian bawah (Hedar, 2018). Setiap kegiatan produksi minyak bumi wajib melakukan pengelolaan air limbah sehingga memenuhi persyaratan yang ditentukan sebelum dibuang ke lingkungan sesuai dengan Peraturan Menteri Negara Lingkungan Hidup Nomor 19 Tahun 2010 Tentang Baku Mutu Air Limbah Bagi Usaha Dan / Atau Kegiatan Minyak Dan Gas Serta Panas Bumi untuk menghindari terjadinya pencemaran dan kerusakan terhadap lingkungan.

\section{METODE PENELITIAN}

Penelitian dilakukan di Lapangan Sumur Tua Desa Wonocolo, dan pengambilan sampel air dilakukan di Sungai Kragsaan dan Sungai Bungsu yang dilakukan pada bulan Desember 2017. Pada saat dilakukan penelitian produksi minyak mentah pada lapangan tersebut adalah rata-rata 60.820 liter per hari.

Pengambilan contoh air sungai dilakukan secara grab sample (pengambilan sesaat) yang mengacu pada SNI 03-7016-2004 - Tata Cara Pengambilan Contoh dalam Rangka Pemantaun Kualitas Air pada Suatu Daerah Pengaliran Sungai. Titik pengambilan sampel air sungai dilakukan mengacu pada SNI 6989.57:2008 - Metode Pengambilan Contoh Air Permukaan.

Lokasi pengambilan sampel pada air permukaan didasarkan pada 2 lokasi yaitu :

1) Lokasi sumber alamiah, yaitu lokasi 
yang belum pernah atau masih sedikit mengalami pencemaran.

2) Lokasi sumber air tercemar, yaitu lokasi yang telah mengalami perubahan atau di bagian hilir dari sumber pencemar.

Penentuan titik pengambilan sampel mempertimbangkan kemudahan akses, biaya dan waktu sehingga ditentukan titik-titik yang mewakili kualitas air sungai yang mendapat pengaruh dari kegiatan penambangan minyak bumi. Penentuan titik pengambilan sampel air sungai adalah sebagai berikut :

Tabel 1. Titik Lokasi Pengambilan Contoh Penelitian

\begin{tabular}{|c|c|}
\hline Sam & Des \\
\hline $\begin{array}{l}\text { Titik KGD } 1 \\
\text { koordinat }-7,045160 \\
\text { LS dan } 111,663597 \\
\text { BT }\end{array}$ & $\begin{array}{l}\text { merupakan titik up- } \\
\text { stream sungai Krag- } \\
\text { saan sebelum terke- } \\
\text { na dampak kegiatan } \\
\text { penambangan. }\end{array}$ \\
\hline $\begin{array}{l}\text { Titik KGD } 2 \text { deng } \\
\text { koordinat }-7,0404 \\
\text { LS dan } 111,6630 \\
\text { BT }\end{array}$ & $\begin{array}{l}\text { merupakan titik down- } \\
\text { stream sungai Krag- } \\
\text { saan setelah meneri- } \\
\text { ma dampak kegiatan }\end{array}$ \\
\hline
\end{tabular}

\begin{tabular}{|c|c|}
\hline $\begin{array}{l}\text { Titik KGD } 3 \\
\text { koordinat }-7 \text {, } \\
\text { LS dan 111, } \\
\text { BT }\end{array}$ & $\begin{array}{l}\text { merupakan titik down- } \\
\text { stream sungai Krag- } \\
\text { saan setelah meneri- } \\
\text { ma dampak kegiatan } \\
\text { penambangan, teta- } \\
\text { pi belum menerima } \\
\text { dampak kegiatan lain- } \\
\text { nya. }\end{array}$ \\
\hline $\begin{array}{l}\text { Titik KDW } 1 \text { dengan } \\
\text { koordinat }-7,048196 \\
\text { LS dan } 111,65852 \mathrm{BT}\end{array}$ & $\begin{array}{l}\text { titik upstream sungai } \\
\text { Bungsu sebelum ter- } \\
\text { kena dampak kegiatan } \\
\text { penambangan. }\end{array}$ \\
\hline $\begin{array}{l}\text { Titik KDW } 2 \\
\text { koordinat }-7,0 \\
\text { LS dan } 111,6 \\
\text { BT }\end{array}$ & $\begin{array}{l}\text { merupakan titik down- } \\
\text { stream sungai Bung- } \\
\text { su setelah meneri- } \\
\text { ma dampak kegiatan } \\
\text { penambangan. }\end{array}$ \\
\hline $\begin{array}{l}\text { Titik KDW } 3 \text { dengan } \\
\text { koordinat }-7,034643 \\
\text { LS dan } 111,645391 \\
\text { BT }\end{array}$ & $\begin{array}{l}\text { merupakan titik down- } \\
\text { stream sungai Bung- } \\
\text { su setelah meneri- } \\
\text { ma dampak kegiatan } \\
\text { penambangan, teta- } \\
\text { pi belum menerima } \\
\text { dampak kegiatan lain- } \\
\text { nya. }\end{array}$ \\
\hline
\end{tabular}

Analisis data hasil uji kualitas air sungai dibandingkan terhadap baku mutu air sungai yang digunakan berdasarkan Peraturan Pemerintah Rebuplik Indonesia No. 82 Tahun 2001 tentang Pengelolaan Kualitas Air dan Pengendalian Pencemaran Air.

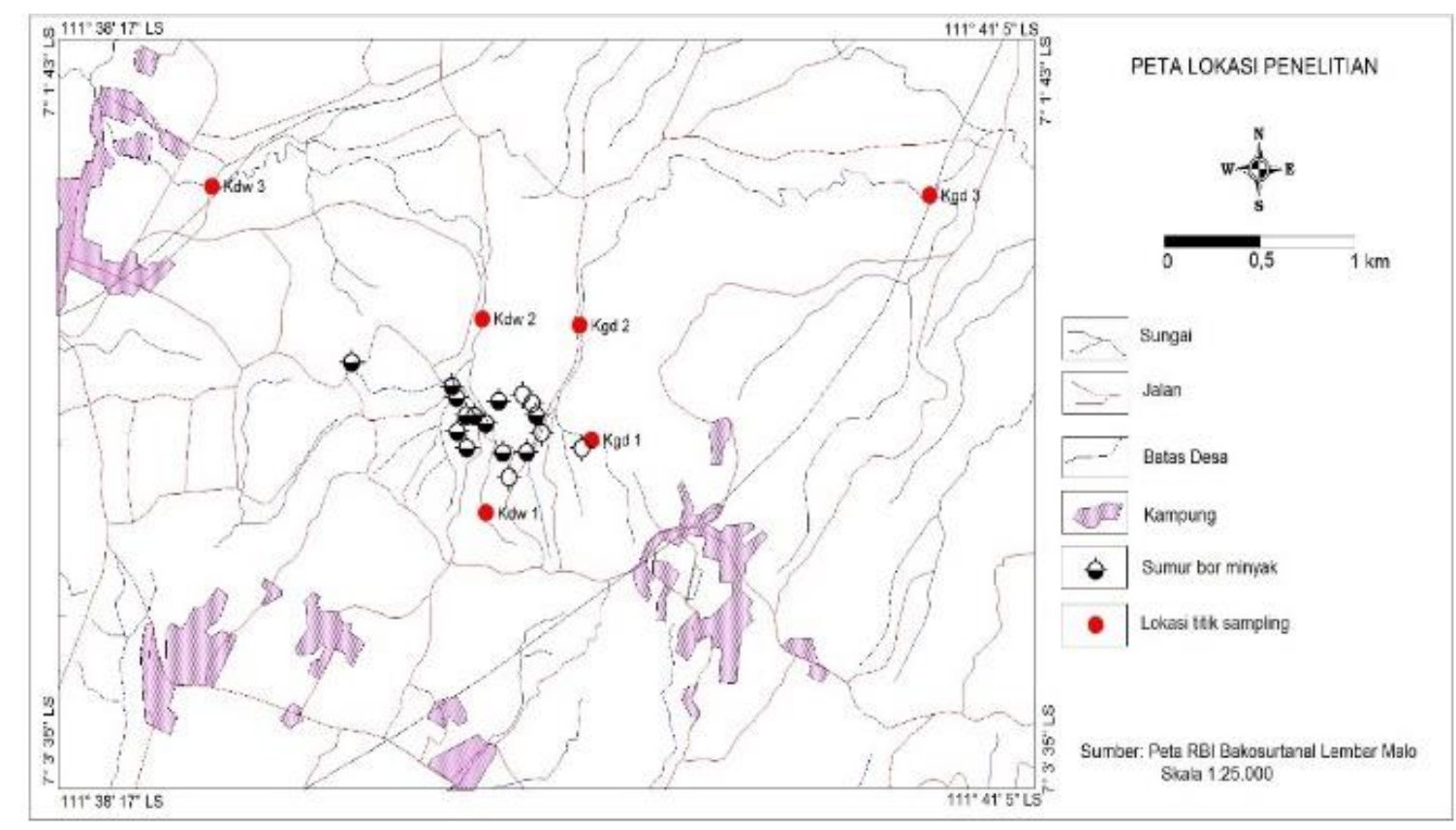

Gambar 1. Lokasi Penelitian 
HASIL PENELITIAN DAN PEMBAHASAN A. Kualitas Air Terproduksi

Berdasarkan Permen ESDM No.1 Tahun 2008 tentang Pedoman Pengusahaan Pertambangan Minyak Bumi Pada Sumur Tua dan dituangkan pula pada Surat Keputusan Kepala BP Migas Nomor 023/PTK/III/2009 tentang Pedoman Tata Kerja Pengusahaan Pertambangan Minyak Bumi Pada Sumur Tua, dalam memproduksi minyak bumi KUD atau BUMD wajib bertanggung jawab atas aspek keselamatan, kesehatan kerja dan pengelolaan lingkungan hidup. Dari hasil survei lapangan didapatkan bahwa kegiatan produksi minyak lapangan Wonocolo belum memiliki IPAL sehingga air terproduksi yang dihasilkan langsung dialirkan ke parit atau sungai, dan pada beberapa sumur yang berdekatan air terproduksi dialirkan ke balong kecil untuk dilakukan penyaringan minyak lebih lanjut sebelum dibuang ke sungai.

Setiap kegiatan produksi minyak bumi wajib melakukan pengelolaan air limbah sehingga memenuhi persyaratan yang ditentukan sebelum dibuang ke lingkungan sesuai dengan Permen LH No. 19 Tahun 2010 tentang Baku Mutu Air Limbah Bagi Usaha Dan/Atau Kegiatan Minyak Dan Gas Serta Panas Bumi untuk menghindari terjadinya pencemaran dan kerusakan terhadap lingkungan. Hasil analisis air limbah air terproduksi yang diambil dari 6 titik sumur pada lapangan Wonocolo disajikan pada tabel 2.

Dari hasil pengukuran air terproduksi dapat diketahui bahwa untuk parameter suhu, $\mathrm{pH}, \mathrm{H} 2 \mathrm{~S}$ dan Fenol konsentrasinya masih dibawah baku mutu. Sedangkan untuk pengukuran TDS, COD, NH3 dan minyak dan lemak dengan rata-rata konsentrasi berturut-

Tabel 2. Konsentrasi Air Terproduksi Pada Lapangan Wonocolo

\begin{tabular}{|l|c|c|c|c|c|}
\hline \multirow{2}{*}{ Parameter } & \multirow{2}{*}{ Satuan } & \multirow{2}{*}{ Baku Mutu } & \multicolumn{3}{c|}{ Konsentrasi Air Terproduksi } \\
\cline { 4 - 6 } & & & Min & Maks & rata-rata \\
\hline Suhu & ${ }^{0} \mathrm{C}$ & 45 & 33,5 & 38,6 & 36,8 \\
TDS & $\mathrm{mg} / \mathrm{L}$ & 4000 & 3140 & 26934 & 8753 \\
$\mathrm{pH}$ & - & $6-9$ & 7,17 & 7,79 & 7,56 \\
$\mathrm{COD}$ & $\mathrm{mg} / \mathrm{L}$ & 300 & 389 & 147.685 & 28.578 \\
$\mathrm{NH}_{3}-\mathrm{N}$ & $\mathrm{mg} / \mathrm{L}$ & 10 & 7,21 & 42 & 15,9 \\
Srmber : Data primer, 2018 & $\mathrm{mg} / \mathrm{L}$ & 1 & 0,306 & 0,552 & 0,436 \\
Fenol & $\mathrm{mg} / \mathrm{L}$ & 2 & 0,137 & 0,440 & 0,307 \\
Minyak dan Lemak & $\mathrm{mg} / \mathrm{L}$ & 25 & 90,6 & 837 & 310 \\
\hline
\end{tabular}

turut yaitu $8.753 \mathrm{mg} / \mathrm{L} ; 28.578 \mathrm{mg} / \mathrm{L} ; 15,9$ $\mathrm{mg} / \mathrm{L} ; 310 \mathrm{mg} / \mathrm{L}$ telah melampaui baku mutu yang dipersyaratkan.

Konsentrasi TDS yang mengambarkan salinitas atau kandungan garam pada air terproduksi kadarnya dapat bervariasi dari $1.000 \mathrm{mg} / \mathrm{L}$ - $400.000 \mathrm{mg} / \mathrm{L}$ (Guerra et al, 2011). Salinitas pada air terproduksi terutama disebabkan oleh kandungan natrium dan klorida terlarut, terdapat juga kandungan calcium, magnesium dan potasium terlarut dengan kadar yang lebih kecil (Neff, 2002).
Kandungan natrium yang tinggi bersaing dengan kalsium, magnesium dan potasium untuk penyerapan oleh akar tanaman. dalam air terproduksi dapat menyebabkan degradasi pada tanah, oleh karena itu kelebihan natrium dapat menyebabkan defisiensi kation lain dan menyebabkan struktur tanah yang buruk serta menghambat infiltrasi air di dalam tanah (Guerra et al., 2011).

Konsentrasi NH3 dalam air terproduksi bisa bervariasi, beberapa air terproduksi mengandung konsentrasi NH3 yang sangat 
rendah, di lain sisi konsentrasi NH3 dalam air terproduksi bisa mencapai $650 \mathrm{mg} / \mathrm{L}$. NH3 dapat terbentuk oleh degradasi bakteri dari senyawa organo-nitrogen dalam formasi (Neff, 2002).

Kandungan air terproduksi yang lain yang dapat berpotensi menimbulkan kerusakan lingkungan adalah bahan organik. Bahan organik dalam air terproduksi dapat berbentuk minyak yang terdispersi dan tersuspensi di dalam air. Kandungan minyak yang masih tinggi di dalam air terproduksi dapat meningkatkan nilai BOD pada badan air penerima limbah tersebut. Penelitian yang terdahulu telah membuktikan bahwa kandungan minyak dan lemak dalam air terproduksi berasosiasi dengan tingginya nilai BOD dan COD (Gazali et al., 2017). Tingginya parameter minyak dan lemak pada air buangan kegiatan produksi lapangan sumur tua Wonocolo disebabkan karena belum sempurna pemisahan air dan minyak dalam bak penampung, dan air terproduksi langsung dibuang tanpa melewati water treatment lebih lanjut.

\section{A. Kualitas Air Sungai}

Parameter dan baku mutu yang digunakan pada analisis kualitas air sungai adalah parameter sesuai dengan Peraturan Pemerintah No. 82 Tahun 2001 tentang pengelolaan
Kualitas dan Pengendalian Pencemaran Air. Parameter ditentukan berdasarkan indikasi sumber pencemar yang ada akibat kegiatan penambangan minyak bumi, sedangkan untuk baku mutu karena belum ditetapkan kelas air untuk sungai Bungsu dan sungai Kragsaan maka digunakan baku mutu air kelas II, yaitu air yang peruntukannya dapat digunakan untuk prasarana/sarana rekreasi air, pembudidayaan ikan air tawar, peternakan, air untuk mengairi pertanaman dan atau peruntukan lain yang sama dengan kegunaan tersebut. Hasil analisis kualitas air sungai Bungsu dan sungai Kragsaan pada titik yang berbeda disajikan pada tabel 3 dan tabel 4.

Dari hasil analisis dapat dilihat pada sungai Bungsu dan sungai Kragsaan daerah hulu yaitu titik KDW1 dan KGD2 nilai untuk semua parameter masih dibawah baku mutu air kelas II, hal ini menandakan kondisi perairan masih cukup bagus karena merupakan daerah hulu sungai yang kondisi airnya masih relatif alami. Sedangkan pada titik KDW2 dan KGD2 semua parameter kecuali $\mathrm{pH}$ dan suhu konsentrasinya telah melampaui baku mutu kelas II sebagaimana yang tercantum dalam PP No. 82 Tahun 2001. Pada tulisan ini pembahasan difokuskan pada parameter TDS, DO, COD, BOD dan minyak dan lemak.

Dari hasil analisis konsentrasi TDS menunjukkan bahwa pada kondisi alamiahnya Tabel 3. Hasil Analisis Kualitas Air Sungai Bungsu

\begin{tabular}{|l|c|c|c|c|c|}
\hline \multirow{2}{*}{ Parameter } & \multirow{2}{*}{ Satuan } & Baku Mutu & \multicolumn{3}{c|}{ Titik Pengambilan Sampel } \\
\cline { 3 - 6 } & & Kelas 2 & KDW1 & KDW2 & KDW3 \\
\hline Suhu & ${ }^{0} \mathrm{C}$ & \pm 3 & 30,0 & 35,0 & 31,0 \\
$\mathrm{TSS}$ & $\mathrm{mg} / \mathrm{L}$ & 50 & 4,20 & 209 & 20,5 \\
$\mathrm{TDS}$ & $\mathrm{mg} / \mathrm{L}$ & 1000 & 608 & 5397 & 2176 \\
$\mathrm{pH}$ & - & $6-9$ & 7,20 & 7,60 & 7,48 \\
$\mathrm{DO}$ & $\mathrm{mg} / \mathrm{L}$ & 4 & 7,02 & 3,54 & 5,50 \\
$\mathrm{COD}$ & $\mathrm{mg} / \mathrm{L}$ & 25 & 7,00 & 424 & 64,0 \\
$\mathrm{BOD}$ & $\mathrm{mg} / \mathrm{L}$ & 3 & 0,97 & 100,6 & 8,81 \\
$\mathrm{NH}_{3}-\mathrm{N}$ & $\mathrm{mg} / \mathrm{L}$ & - & 0,184 & 6,21 & 1,52 \\
$\mathrm{H}_{2} \mathrm{~S}$ & $\mathrm{mg} / \mathrm{L}$ & 0,002 & $<0,002$ & 0,427 & 0,096 \\
Fenol & $\mu \mathrm{g} / \mathrm{L}$ & 1 & $<1$ & 414 & 331 \\
Minyak dan Lemak & $\mu \mathrm{g} / \mathrm{L}$ & 1000 & 646 & 9455 & 2744 \\
\hline
\end{tabular}

Sumber : Data Primer, 2018; Baku Mutu Air Sungai mengacu PP No.82 Tahun 2001. 
Tabel 4. Hasil Analisis Kualitas Air Sungai Kragsaan

\begin{tabular}{|l|c|c|c|c|c|}
\hline \multirow{2}{*}{ Parameter } & \multirow{2}{*}{ Satuan } & Baku Mutu & \multicolumn{3}{c|}{ Titik Pengambilan Sampel } \\
\cline { 2 - 6 } & & Kelas 2 & KGD1 & KGD2 & KGD3 \\
\hline Suhu & ${ }^{0} \mathrm{C}$ & \pm 3 & 30,0 & 38,0 & 28,0 \\
TSS & $\mathrm{mg} / \mathrm{L}$ & 50 & 4,00 & 96,2 & 17,7 \\
TDS & $\mathrm{mg} / \mathrm{L}$ & 1000 & 600 & 3932 & 914 \\
$\mathrm{pH}$ & - & $6-9$ & 7,27 & 7,23 & 7,41 \\
$\mathrm{DO}$ & $\mathrm{mg} / \mathrm{L}$ & 4 & 6,82 & 3,78 & 5,82 \\
$\mathrm{COD}$ & $\mathrm{mg} / \mathrm{L}$ & 25 & 5,80 & 136 & 40,7 \\
$\mathrm{BOD}$ & $\mathrm{mg} / \mathrm{L}$ & 3 & 0,49 & 37,0 & 5,42 \\
$\mathrm{NH}_{3}-\mathrm{N}$ & $\mathrm{mg} / \mathrm{L}$ & - & 0,064 & 3,91 & 0,304 \\
$\mathrm{H}_{2} \mathrm{~S}$ & $\mathrm{mg} / \mathrm{L}$ & 0,002 & $<0,002$ & 0,165 & $<0,002$ \\
Fenol & $\mu \mathrm{g} / \mathrm{L}$ & 1 & $<1$ & 389 & 273 \\
Minyak dan Lemak & $\mu \mathrm{g} / \mathrm{L}$ & 1000 & 737 & 1621 & 752 \\
\hline
\end{tabular}

Sumber : Data Primer, 2018; Baku Mutu Air Sungai mengacu PP No.82 Tahun 2001

pada titik KDW1 dan KGD1 yang merupakan hulu sungai sebelum menerima dampak kegiatan penambangan konsentrasi TDS masih dibawah baku mutu air kelas 2 yaitu sebesar $608 \mathrm{mg} / \mathrm{L}$ dan. $600 \mathrm{mg} / \mathrm{L}$. Sedangkan konsentrasi pada titik KDW2 adalah 5397 mg/L dan KGD2 3932 mg/L, konsentrasi TDS jauh melebihi baku mutu air kelas 2 . Hal ini disebabkan badan air telah menerima sumber pencemar air terproduksi dengan kandungan TDS yang tinggi. Konsentrasi TDS pada titik KDW3 adalah $2176 \mathrm{mg} / \mathrm{L}$ masih dibawah standar baku mutu air kelas 2 , hal ini disebabkan karena selain tingginya konsentrasi pencemar yang masuk juga disebabkan kondisi sungai yang tidak terlalu besar sehingga belum mampu mengencerkan

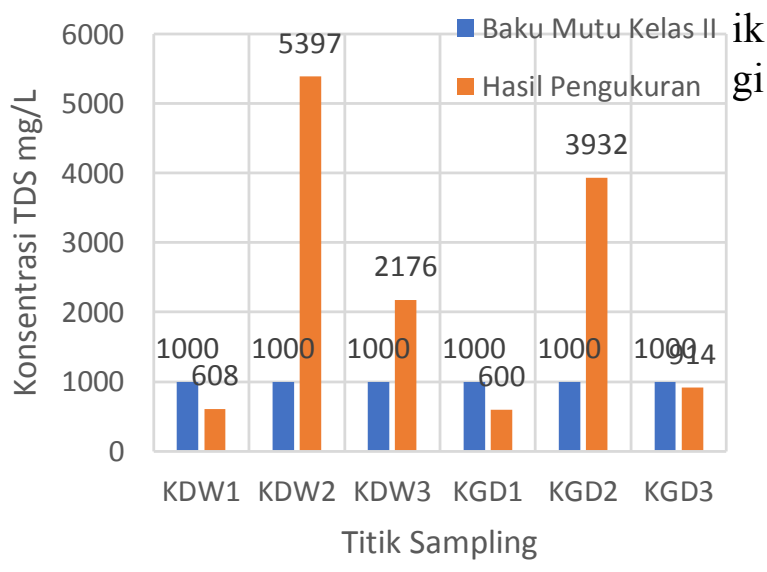

Gambar 2. Hasil Pengukuran TDS Sungai

36 Bungsu dan Sungai Kragsaan
Padatan terlarut total adalah bahan-bahan terlarut dan koloid yang berupa senyawasenyawa kimia seperti bahan anorganik yang berupa ion-ion yang biasa ditemukan di perairan (Andini, 2017). TDS biasanya berasal dari garam-garam anorganik dan sejumlah bahan organik yang terlarut dalam air (Akkaraboyina \& Raju, 2012). Pada air tawar nilai TDS berada pada kisaran konsentrasi 0-1000 mg/L (Effendi, 2003).Nilai DO hasil pengukuran pada Sungai Kragsaan dan Sungai Bungsu berkisar antara 3,54-7,02 mg/L. Nilai DO pada titik KDW1 adalah 7,02 $\mathrm{mg} / \mathrm{L}$ dan KGD1 adalah 6,82 masih cukup bagus karena merupakan daerah hulu sungai yang kondisi airnya masih relatif alami dengan kualitas air yang masih baik. Sedangkan pada titik KDW2 dan KGD2 konsentrasi DO mengalami penurunan yang signifikan yaitu $3,54 \mathrm{mg} / \mathrm{L}$ dan $3,78 \mathrm{mg} / \mathrm{L}$.

Hal ini disebabkan karena sungai mengalami pencemaran yang tinggi oleh limbah minyak yang terbawa oleh air terproduksi dan keadaan aliran sungai yang tidak begitu deras. Persentase oksigen terlarut di sekeliling perairan dipengaruhi oleh suhu perairan, salinitas perairan, ketinggian tempat dan plankton (di udara yang panas, oksigen terlarut akan turun). Daya larut oksigen dalam air laut lebih rendah jika dibandingkan dengan daya larutnya dalam air tawar. Daya larut oksigen dalam air limbah kurang dari 95\%

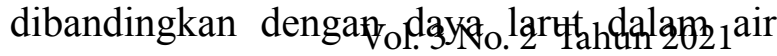
tawar (Setiaji, 1995). 
Oksigen bebas dalam air dapat berkurang bila dalam air terdapat kotoran/limbah organik yang degradable (Darsono, 1992). Konsentrasi DO pada titik KDW3 adalah 5,5 $\mathrm{mg} / \mathrm{L}$ dan KGD3 adalah 5,82 $\mathrm{mg} / \mathrm{L}$, dimana konsentrasi DO sudah mengalami peningkatan dan memenuhi baku mutu air kelas 2. Hal ini menunjukkan bahwa baik sungai Kragsaan dan Sungai Bungsu proses self purification telah berjalan optimal. Semakin panjang jarak maka kemampuan self purification sungai akan semakin bagus yang ditandai dengan semakin meningkatnya nilai DO dalam air dengan catatan tidak ada masukan beban pencemar dari luar (Hendrasarie \& Cahyarani, 2010).
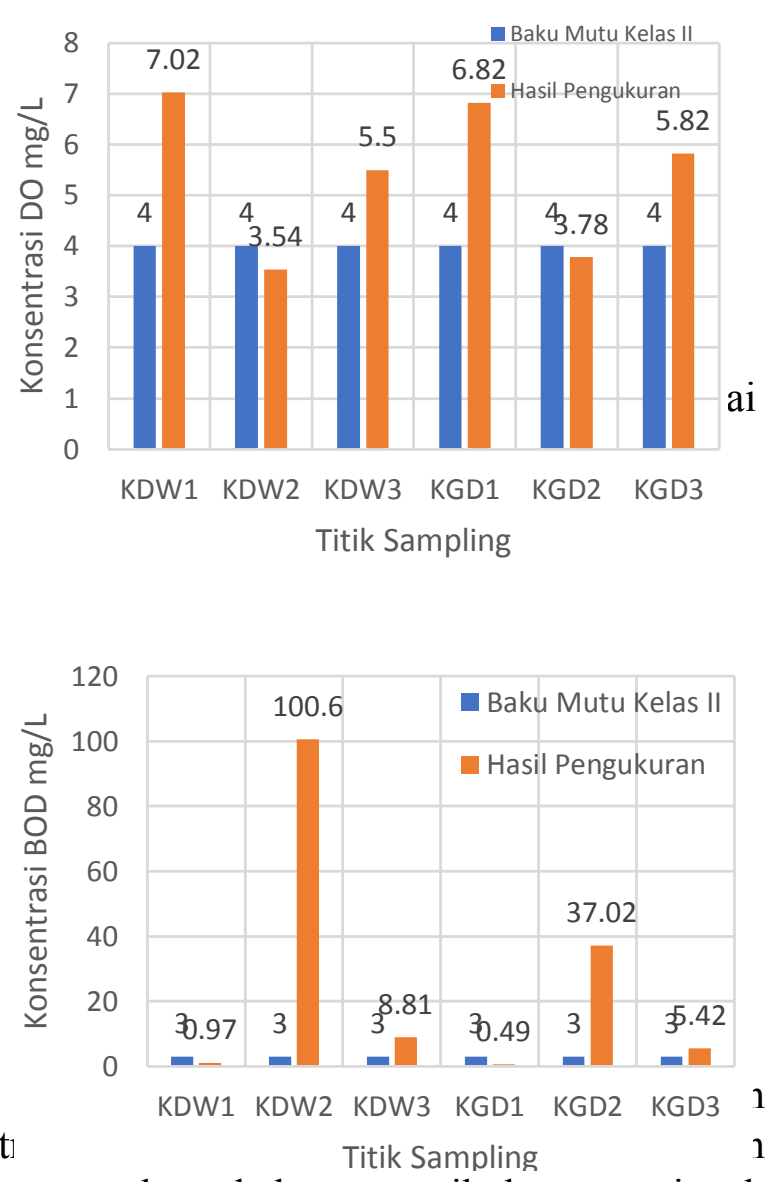

mengandung bahan organik berupa minyak dan lemak dengan konsentrasi yang yang tinggi.

Bahan buangan organik umumnya berupa limbah yang dapat membusuk atau terdegradasi oleh mikroorganisme, sehingga bila dibuang ke peraiaran akan menaikkan BOD $_{5}$ (Rahmawati, 2011) Hal ini terlihat dari hasil analisis BOD5 pada titik KDW2 dan KGD3 BOD5 adalah jumlah oksigen yang dibutuhkan oleh mikroorganisme dalam lingkungan air untuk memecah (mendegradasi) bahan buangan organik yang ada dalam air menjadi karbondioksida dan air. Semakin besar kadar $\mathrm{BOD}_{5}$, maka merupakan indikasi bahwa perairan tersebut telah tercemar.

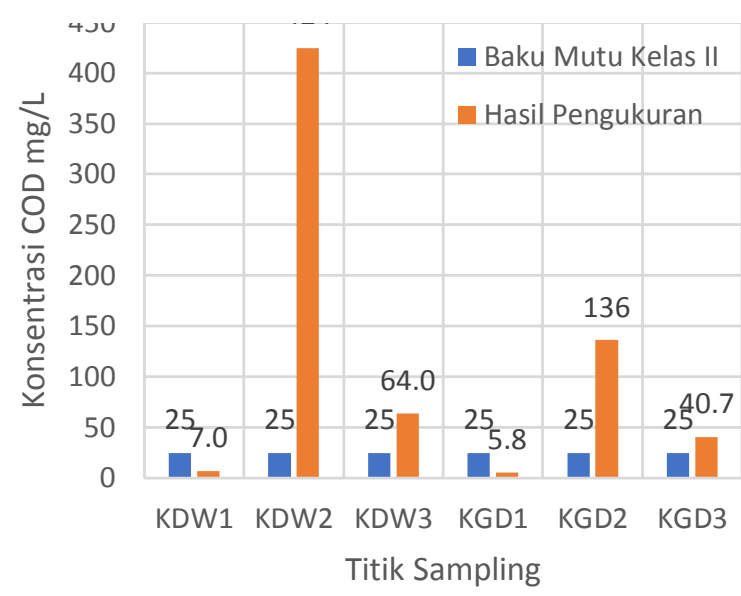

menunjukkan bahwa terdapat kandungan senyawa organik yang tinggi dalam peraiaran tersebut (Salmin, 2005). Kadar maksimum $\mathrm{BOD}_{5}$ yang diperkenankan untuk kepentingan air minum dan menopang kehidupan organisme akuatik adalah 3,0-6,0 mg/L (Dhany, 2015). Hasil pemantauan dan pengukuran nilai COD pada Sungai Kragsaan dan Sungai Bungsu pada penelitian ini dapat dilihat pada Gambar 10. Nilai COD pada kedua sungai tersebut memiliki tren yang sama dengan nilai BOD. Menurut Ardhani (2014) nilai COD merupakan indikasi pencemar organik biodegradable dan non-biodegradable sehingga penambahan pencemar organik biodegradable $\left(\mathrm{BOD}_{5}\right)$ juga mempengaruhi perubahan nilai COD sehingga 
idealnya jika terjadi peningkatan nilai $\mathrm{BOD}_{5}$ maka akan terjadi peningkatan terhadap nilai COD. Nilai COD pada perairan yang tidak tercemar biasanya $<20 \mathrm{mg} / \mathrm{L}$. Kelebihan pengukuran COD dibandingkan dengan BOD adalah dapat menguji air limbah yang beracun, yang tidak dapat diuji oleh BOD karena bakteri akan mati serta membutuhkan waktu pengujian lebih singkat yaitu 3 jam (Yuliastuti, 2011).

Dari hasil analisis COD, BOD dan DO dapat dilihat tren bahwa semakin tinggi pencemar organik yang masuk ke perairan (titik KDW2 dan titik KGD2) maka nilai konsentrasi BOD akan mengalami peningkatan yang pada saat bersamaan berbanding lurus dengan peningkatan nilai konsentrasi COD, akan tetapi untuk nilai konsentrasi DO mengalami laju penurunan dan berbanding terbalik dengan nilai konsentrasi COD dan BOD.

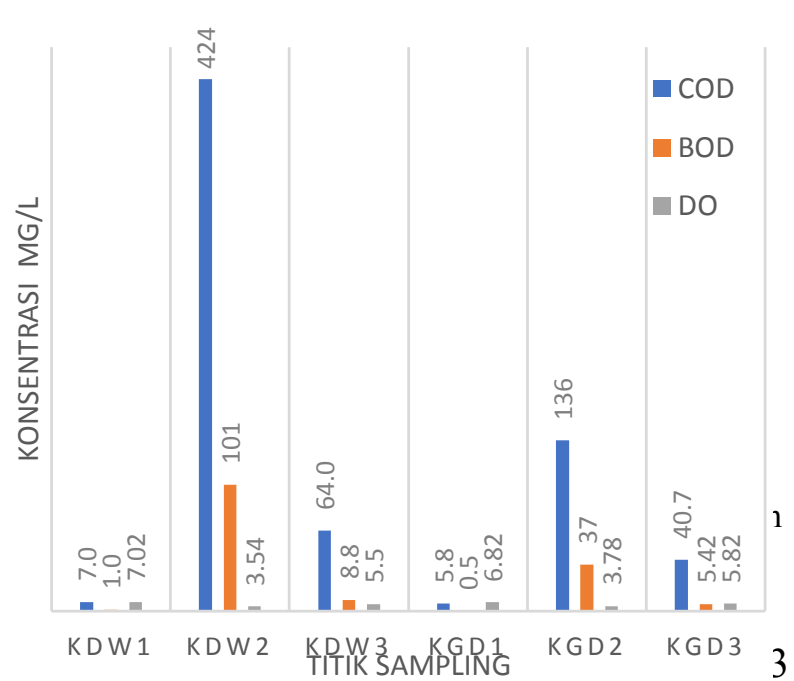

dan KGD3, ketika nilai konsentrasi COD dan BOD menurun disaat yang sama nilai konsentrasi DO akan meningkat. Semakin banyak oksigen yang dikonsumsi dalam proses dekomposisi $\mathrm{BOD}_{5}$ dan oksidasi COD maka akan mengurangi jumlah oksigen yang terlarut dalam air. Perbandingan nilai konsentrasi COD, BOD dan DO dapat dilihat pada gambar 5 .

Konsentrasi minyak dan lemak pada titik KDW2, KGD2 dan KDW3 masing-masing sebesar $9.455 \mu \mathrm{g} / \mathrm{L}, 1.621 \mu \mathrm{g} / \mathrm{L}$ dan 2.744 $\mu \mathrm{g} / \mathrm{L}$ nilainya telah melebihi baku mutu air kelas II. Tingginya konsentrasi minyak dan lemak pada titik tersebut tidak terlepas dari air limbah air terproduksi yang dibuang tanpa melalui proses pengolahan limbah sehingga kandungan minyak dan lemak dalam air terproduksi masih cukup tinggi. Pada titik KDG3 konsentrasi minyak dan lemak sebesar $752 \mu \mathrm{g} / \mathrm{L}$ masih dibawah baku mutu air kelas II. Penurunan konsentrasi minyak dan lemak pada titik KDW3 dan KGD3, meskipun pada titik KDW3 nilainya masih melebihi baku mutu, disebabkan oleh pembuatan trap-trap minyak oleh masyarakat pada jarak tertentu untuk menangkap dan mengurangi minyak yang terbawa oleh aliran sungai. Selain itu minyak yang terbawa oleh aliran terperangkap secara alami oleh benda-benda padat seperti ranting pohon dan batu yang menghambat laju aliran sungai.

Pencemaran minyak di dalam air dapat terjadi karena adanya kegiatan eksplorasi minyak bumi, pengilangan minyak kecelakaan transportasi atau kebocoran pipa. Minyak di air dapat berupa minyak terapung dipermukaan, terdispersi secara mekanik, teremulsi, terlarut (ukuran droplet $<5 \mathrm{~mm}$ ), dan minyak yang melekat pada permukaan (Nuryantini \& Wiloso, 2010) 


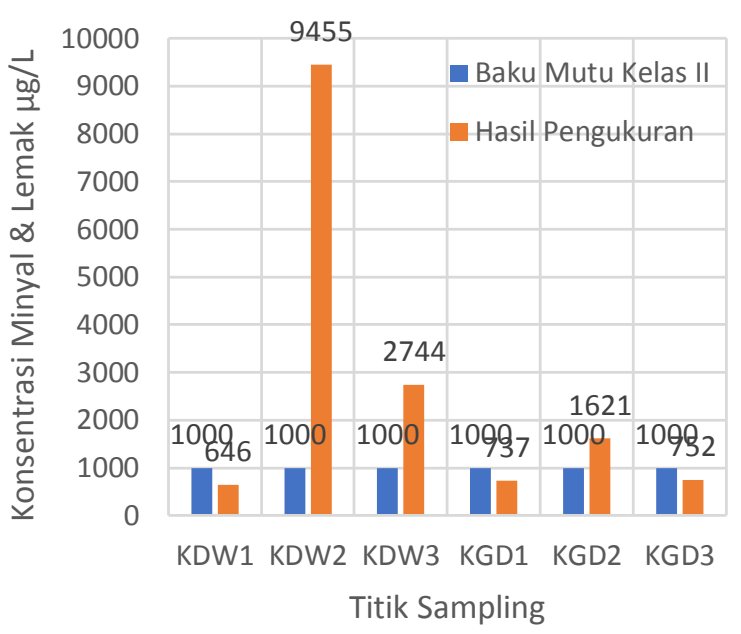

Gambar 7. Hasil Pengukuran Minyak dan Lemak Sungai Bungsu dan Sungai Kragsaan

Minyak dan lemak yang mencemari air sering dimasukkan ke dalam kelompok padatan, yaitu padatan yang mengapung di atas permukaan air. Semua jenis minyak mengandung senyawa-senyawa volatil yang dapat menguap. Sisa minyak yang tidak menguap akan mengalami emulsifikasi yang mengakibatkan air dan minyak bercampur (Fardiaz, 1992). Minyak mempunyai beratjenis lebih kecil dari air sehingga akan membentuk lapisan di permukaan air. Minyak dan lemak merupakan bahan organik bersifat tetap dan sukar diuraikan oleh bakteri (Hardiana S. \& Mukimin, 2014).

Dampak yang nyata dari adanya minyak dan lemak di permukaan air adalah terhalangnya penetrasi sinar matahari yang berarti mengurangi laju fotosintesis di dalam air. Penutupan permukaan air oleh minyak mengurangi masukan oksigen bebas dari udara kedalam air. Sebagian emulsi minyak dan lemak akan mengalami degradasi melalui fotooksidasi spontan dan oksidasi oleh mikroorganisme. Penguraian minyak dan lemak dalam kondisi kurang oksigen akan menyebabkan penguraian yang tidak sempurna sehingga menimbulkan bau tengik (Hendrawan, 2008). Beberapa komponen yang menyusun minyak juga diketahui bersifat racun terhadap hewan dan manusia, tergantung dari struktur dan berat molekulnya. Komponen-komponen hidrokarbon jenuh dapat menyebabkan anastesi dan narkosis pada berbagai hewan tingkat rendah, dan jika terdapat pada konsentrasi tinggi dapat mengakibatkan kematian. Komponenkomponen hidrokarbon aromatik seperti benzene, toluene dan xilen bersifat racun terhadap manusia dan kehidupan lainnya (Fardiaz, 1992).

\section{KESIMPULAN}

Kegiatan penambangan tradisional minyak bumi di Desa Wonocolo menghasilkan konsentrasi air limbah terproduksi yang masih melebihi baku mutu sesuai Peraturan Menteri Lingkungan Hidup No. 19 Tahun 2010. Parameter yang terlampaui yaitu TDS, $\mathrm{COD}, \mathrm{NH}_{3}-\mathrm{N}$, minyak dan lemak. Kualitas air Sungai Bungsu dan Sungai Kragsaan setelah menerima air terproduksi kegiatan penambangan minyak bumi termasuk kategori tidak memenuhi baku mutu untuk air kelas II sebagaimana terlampir dalam PP No.82 Tahun 2001.

Kegiatan penambangan tradisional minyak bumi menjadi faktor terlampauinya baku mutu beberapa parameter karena mempunyai sumber limbah air terproduksi dalam kegiatan tersebut.

\section{DAFTAR PUSTAKA}

Ahmadun, F. R., Pendashteh, A., Abdullah, L. C., Biak, D. R. A., Madeni, S. S., \& Abidin, Z. Z. (2009). Review of Technologies For Oil and Gas Produced Water Treatment. Journal of Hazardous Materials, 170, 530-551. https://doi. org/10.1016/j.jhazmat.2009.05.044

Akkaraboyina, M. K., \& Raju, B. (2012). Time Series Forecasting Of Water Quality Of River Godavari. IOSR Journal of Mechanical and Civil Engineering, 1(3), 
$39-44$.

Andini, A. P. (2017). Strategi Pengelolaan Kualitas Air Sungai Ciujung Berdasarkan Daya Tampung Beban Pencemaran Dengan Metode QUAL2Kw. Universitas Diponegoro.

Ardhani, D. (2014). Pengelolaan Sungai Batanghari Kabupaten Dharmayasa Berdasarkan Daya Tampung Beban Pencemaran Dengan Metode Qual2Kw. Universitas Diponegoro.

Asdak, C. (2010). Hidrologi dan Pengelolaan Daerah Aliran Sungai. Yogyakarta: Gadjah Mada University Press.

Darsono, V. (1992). Pengantar Ilmu Lingkungan. Yogyakarta: Universitas Atmajaya.

Dhany, T. (2015). Strategi Pengelolaan Sungai Berdasarkan Permodelan Daya Tampung Beban Cemar dan Analisis Resiko Lingkungan di DAS Bengawan Solo Hulu, Segmen Kota Surakarta dan Kabupaten Karanganyar. Universitas Diponegoro Semarang.

Effendi, H. (2003). Telaah Kualitas Air Bagi Pengelolaan Sumber Daya dan Lingkungan Perairan. Yogyakarta: Kanisius.

Fardiaz, S. (1992). Polusi Air Dan Udara. Yogyakarta: Kanisius.

Gazali, A. K., Alkali, A. N., Mohammed, Y., Djauro, Y., Muhammed, D. D., \& Kodomi, M. (2017). Environmental Impact of Produced Water and Driiling Waste Discharges from the Niger Delta Petroleum Industry. IOSR Journal of Engineering (IOSRJEN), 07(06), 22503021. Retrieved from http://www.iosrjen. org/Papers/vol7_issue6/Version-1/ D0706012229.pdf

Guerra, K., Dahm, K., \& Dundorf, S. (2011). Oil and Gas Produced Water Management and Beneficial Use in the Western United States. U.S. Department of the Interior Bureau of Reclamation. Denver. https:// doi.org/3180

Hardiana S., S., \& Mukimin, A. (2014). Pengembangan Metode Analisis Parameter Minyak dan Lemak Pada Contoh Uji Air. Retrieved from https://media.neliti.com/media/ publications/127949-ID-none.pdf

Hasiany, S., Noor, E., \& Yani, M. (2015). Clean Production Application for Water Handling Manufactured in Oil and Gas Industry. Journal of Natural Resources and Environment Management, 5(1), 25-32. https://doi.org/10.19081/ jps1.2015.5.2.25

Hedar, Y. (2018a). Pengaruh Kegiatan Penambangan Tradisional Minyak Bumi Pada Sumur Tua Terhadap Kualitas Air Sungai (Studi Kasus Penambangan Ttadisional Minyak Bumi Di Desa Wonocolo Kecamatan Kedewan Kabupaten Bojonegoro). Universitas Diponegoro. Retrieved from http:// eprints.undip.ac.id/64209/

Hedar, Y. (2018b). Pollution Impact and Alternative Treatment for Produced Water. In E3S Web Conf, The 2nd International Conference on Energy, Environmental and Information System (ICENIS 2017) (Vol. 31, 03004,pp. 1-12). https://doi.org/https://doi.org/10.1051/ e3sconf $/ 20183103004$

Hendrasarie, N., \& Cahyarani. (2010). Kemampuan Self Purification Kali Surabaya, Ditinjau Dari Parameter Organik Berdasarkan Model Matematis Kualitas Air. Jurnal Ilmiah Teknik Lingkungan, 2(1). Retrieved from http:// eprints.upnjatim.ac.id/1247/

Hendrawan, D. (2008a). Kualitas Air Sungai Ciliwung Ditinjau dari Parameter Minyak dan Lemak. Jurnal Ilmu-Ilmu Perairan Dan Perikanan Indonesia, 15(2), 85-93. Retrieved from http:// journal.ipb.ac.id/index.php/jippi/ article/view/11\%5Cnhttp://journal. 
ipb.ac.id/index.php/jippi/article/ download/11/4278

Marlena, B., Rasti Juliasari, I., \& Purwanto, A. (2015). Kajian Pengelolaan Lumpur Minyak Bumi di Penambangan Minyak Bumi Sumur Tua di Kabupaten Blora. In Pengelolaan Sumber Daya Alam dan Lingkungan (pp. 98-103). Semarang: Program Pascasarjana Universitas Diponegoro.

Mulyanto, H. R. (2007). Sungai, Fungi dan Sifat-sifatnya. Graha Ilmu Yogyakarta.

Naumi, R. N. (2015). Pertambangan Minyak TradisionaldiDesa Wonocolo, Kecamatan Kedewan, Kabupaten Bojonegoro Tahun 1970-1987. AVATARA, e-Journal Pendidikan Sejarah, 3(1), 135-146.

Neff, J. M. (2002). Produced Water. In Bioaccumulation in Marine Organisms Effect of Contaminants from Oil Well Produced Water (pp. 1-35). Elsevier Ltd. https://doi.org/https://doi.org/10.1016/ B978-008043716-3/50002-6

Nuryantini, \& Wiloso, E. I. (2010). Uji

Metode Analisis Minyak Terdispersi Dalam Air. Jurnal Teknologi Indonesia. Retrieved from http://tekindonesia. blogspot.co.id/2011/05/normal-0-falsefalse-false-en-us-x-none.html

Peraturan Menteri Energi Dan Sumber Daya Mineral Nomor 01 Tahun 2008 Tentang Pedoman Pengusahaan Pertambangan Minyak Bumi Pada Sumur Tua.

Peraturan Menteri Negara Lingkungan Hidup

Nomor 19 Tahun 2010 Tentang Baku Mutu Air Limbah Bagi Usaha Dan / Atau Kegiatan Minyak Dan Gas Serta Panas Bumi.

Peraturan Pemerintah Nomor 82 Tahun 2001

Tentang Pengelolaan Kualitas Air dan Pengendalian Pencemaran Air.

Peraturan Pemerintah Republik Indonesia Nomor 38 Tahun 2011 Tentang Sungai (2011).

Priyambada, I. B., Oktiawan, W., \& Suprapto,
R. P. E. (2008). Analisa Pengaruh Perbedaan Fungsi Tata Guna Lahan Terhadap Beban Cemaran BOD Sungai (Studi Kasus : Sungai Serayu - Jawa Tengah). Jurnal PRESIPITASI, 5(2), 5562.

Raharjo,A. D. U. (2016). Evaluasi Perhitungan Potensi Sumur Minyak Tua dengan Water Cut Tinggi. Prosiding Seminar Nasional Aplikasi Sains \& Teknologi (SNAST), 124-129.

Rahmawati, D. (2011). Pengaruh Kegiatan Industri Terhadap Kualitas Air Sungai Diwak Di Bergas Kabupaten Semarang Dan Upaya Pengendalian Pencemaran Sungai. Universitas Diponegoro Semarang.

Salmin. (2005). Oksigen Terlarut (DO) Dan Kebutuhan Oksigen Biologi (BOD) Sebagai Salah Satu Indikator Untuk Menentukan Kualitas Perairan. Oseana, $X X X(3), 21-26$. Retrieved from oseanografi.lipi.go.id/dokumen/oseana $\operatorname{xxx}(3) 21-26 . p d f$

Schifter, I., Macias, C. G., Coria, L. S., Reyna, G. S., \& Lozano, C. G. (2015). Long-term effects of discharges of produced water the marine environment from petroleumrelated activities at Sonda de Campeche , Gulf of México. Environ Monit Assess, 187(723), 1-24. https://doi.org/10.1007/ s10661-015-4944-1

Setiaji, B. (1995). Baku Mutu Limbah Cair Untuk Parameter Fisika, Kimia Pada Kegiatan MIGAS dan Panas Bumi. In Lokakarya Kajian Ilmiah tentang Komponen, Parameter, Baku Mutu Lingkungan dalam Kegiatan Migas dan Panas Bumi. Yogyakarta: PPLH UGM.

Siahaan, R., Indrawan, A., Soedharma, D., \& Prasetyo, L. B. (2011). Water Quality of Cisadane River, West Java-Banten. Scientific Journal of Science, 11(2).

Veil, J. A., Puder, M. G., Elcock, D., \& Redweik, R. J. J. (2004). A White 
Paper Describing Produced Water from Production of Crude Oil, Natural Gas, and Coal Bed Methane.

Wardhana, W. A. (2004). Dampak Pencemaran Lingkungan. Andi Offset.

Yuliastuti, E. (2011). Kajian Kualitas Air Sungai Ngringo Karanganyar Dalam Upaya Pengendalian Pencemaran Air. Universitas Diponegoro Semarang. 